\title{
Calculation of Air-Slide Conveyor
}

\author{
Halima Hadziahmetovic \& Ejub Dzaferovic
}
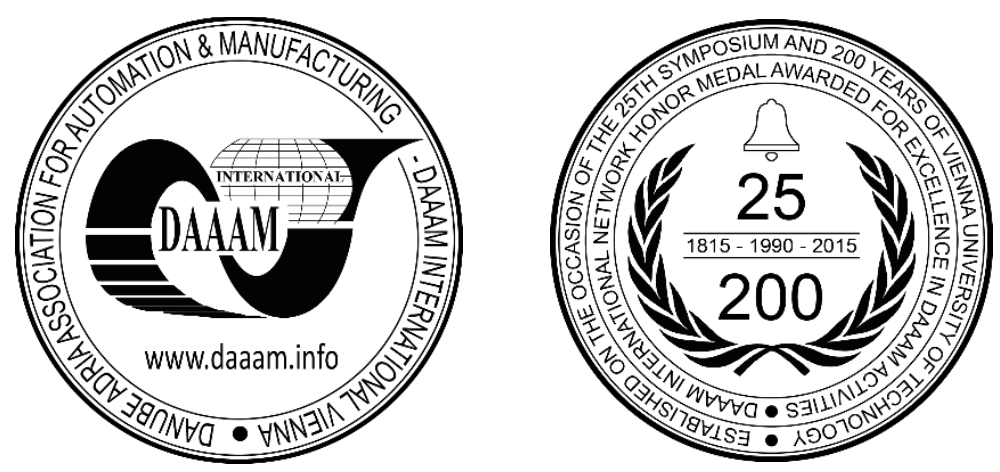

This Publication has to be referred as: Hadziahmetovic, H[alima] \& Dzaferovic, E[jub] (2017). Calculation of AirSlide Conveyor, Proceedings of the 28th DAAAM International Symposium, pp.0268-0273, B. Katalinic (Ed.), Published by DAAAM International, ISBN 978-3-902734-11-2, ISSN 1726-9679, Vienna, Austria

DOI: $10.2507 / 28$ th.daaam.proceedings.036

\begin{abstract}
Pneumatic conveying involves the transportation powder, granular and piece of material and is based on the phenomenon that at the appropriate speed of air in the pipeline, the solid particles are brought in the desired direction. If inlet air velocity is too high the material flow rate may be reduced, the power requirements will be excessive, and operating problems will be severe. Considering the advantages that air-slide conveyors can offer in relation to pneumatic conveying systems especially in terms of low power consumption and operating problems associated with abrasive particles, such as erosive wear of system components and degradation of friable particles. In this paper is presented design calculation of air- slide conveyor in the thermal power plant.
\end{abstract}

Keywords: particle; pneumatic conveying; air- slide conveyor; ventilator

\section{Introduction}

Pneumatic conveying is one of the key technologies in almost all branches of industry. Parallel to the development of science and technology, there was also the development of pneumatic components and systems, which contributed to the expansion of its application. Due to the many advantages, pneumatic conveying is used more than mechanically, mainly for the transport of dry, powdered and fine grained materials.

Pneumatic conveying is used to: unload and transfer dust and grain materials (cement, cereals, plant seeds and the like), transport vehicles by means of which they are transported in bulk (wagons, car tanks, cargo ships), transport of coal to powder in thermoelectric power plants and large boiler plants, transfer of electro-filter fly ash in thermal power plants, transport of cereals and their products in mills and silos, transport of sawdust and waste in wood industry and furniture factories, transfer of detergent to powder and grain materials in the chemical and process industry, sugar in the crystal, as well as other components in the food industry, the transfer of smoked tobacco in cigarette factories, the transportation and discharge of all kinds of dust collected by suction of contaminated premises and transport of administrative consignments. The area of application of pneumatic conveying to the industry is wide, especially in developed economy countries (Fig. 1.and Fig. 2.) $[1,3,6]$. 


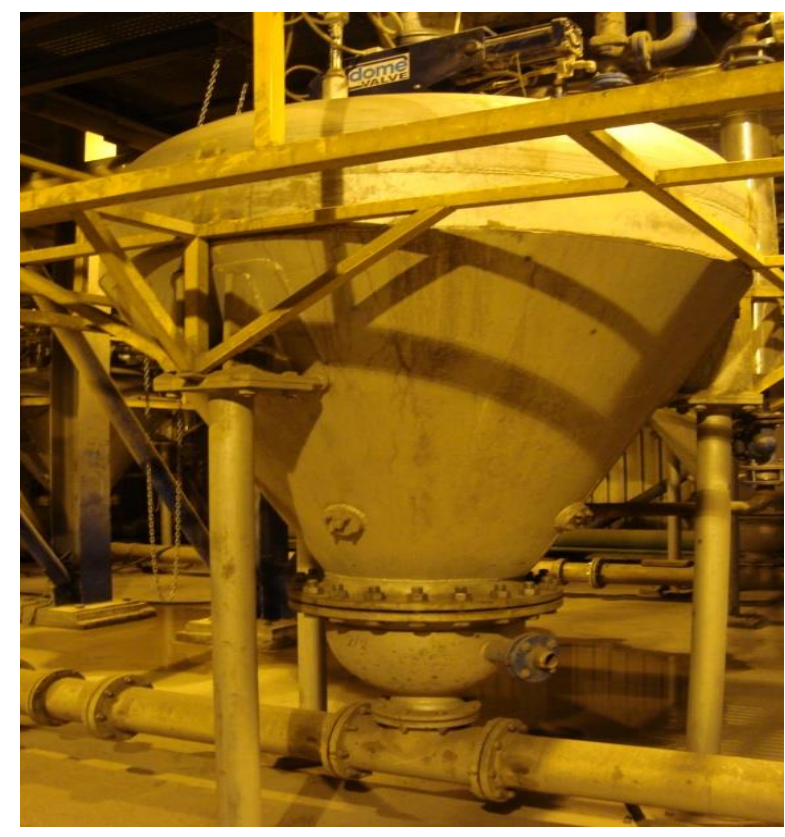

Fig. 1. Transport of fly ash [8]

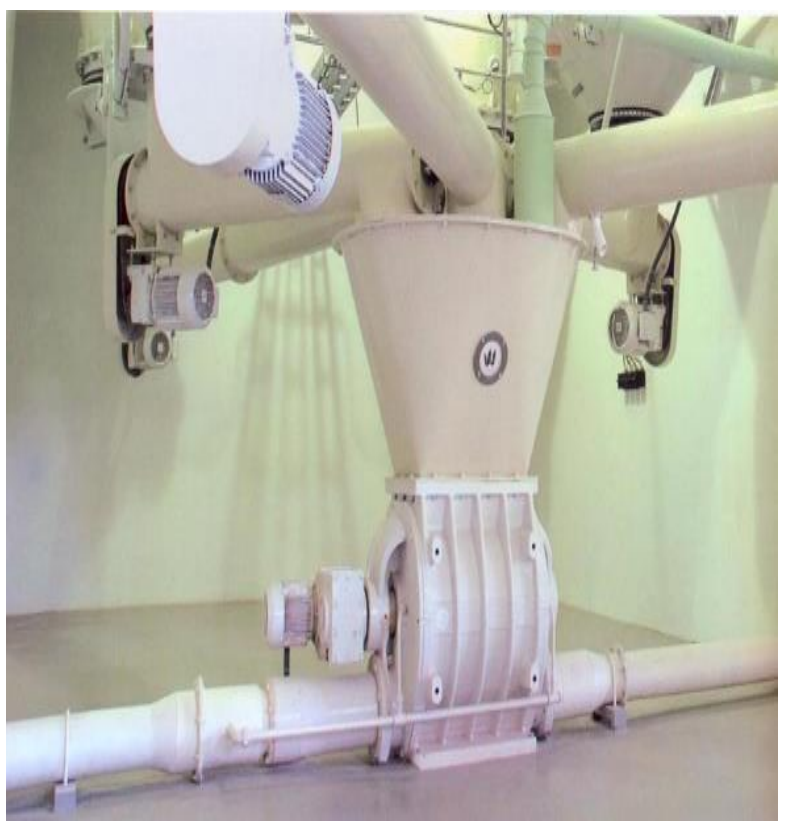

Fig. 2. Transport of flour [8]

Pneumatic conveying material is based on the principle of transferring solid particles at appropriate gas velocities in the pipeline. The required fluid pressure and flow depend on the quantity and type of material as well as the shape and length of the transport path. Each solid material provided in the dispersion form has different transport characteristics and when designing and modeling the transport system it is necessary to know these properties. The transport is realized by inserting the material into the flow of fluid into the pipeline through which it is transferred to a certain location. Subsequently, the material is separated from the material, which is discharged through the particle separator (cyclones, bag filters) into the atmosphere and the material is sent to the silo or to the further production $[4,5,6]$.

With pneumatic conveying systems it is critical that the conveying line inlet air velocity is correctly specified. Because air is compressible, and very much higher air pressures are used in pneumatic conveying than in air-slide conveying, ensuring that the correct inlet velocity is achieved and maintained in a pneumatic conveying system is not a simple matter. If this inlet air velocity is too high the material flow rate may be reduced, the power requirements will be excessive, and operating problems will be severe. With the installation of air-slide conveyors, it will be provided in terms of low power consumption and operating problems associated with abrasive particles, such as erosive wear of system components are almost nonexistent [2,5]. In this paper is presented the design calculation of air-slide conveyor in the thermal power plant and the air-slide conveyor is in the process of being installed in the thermal power plant.

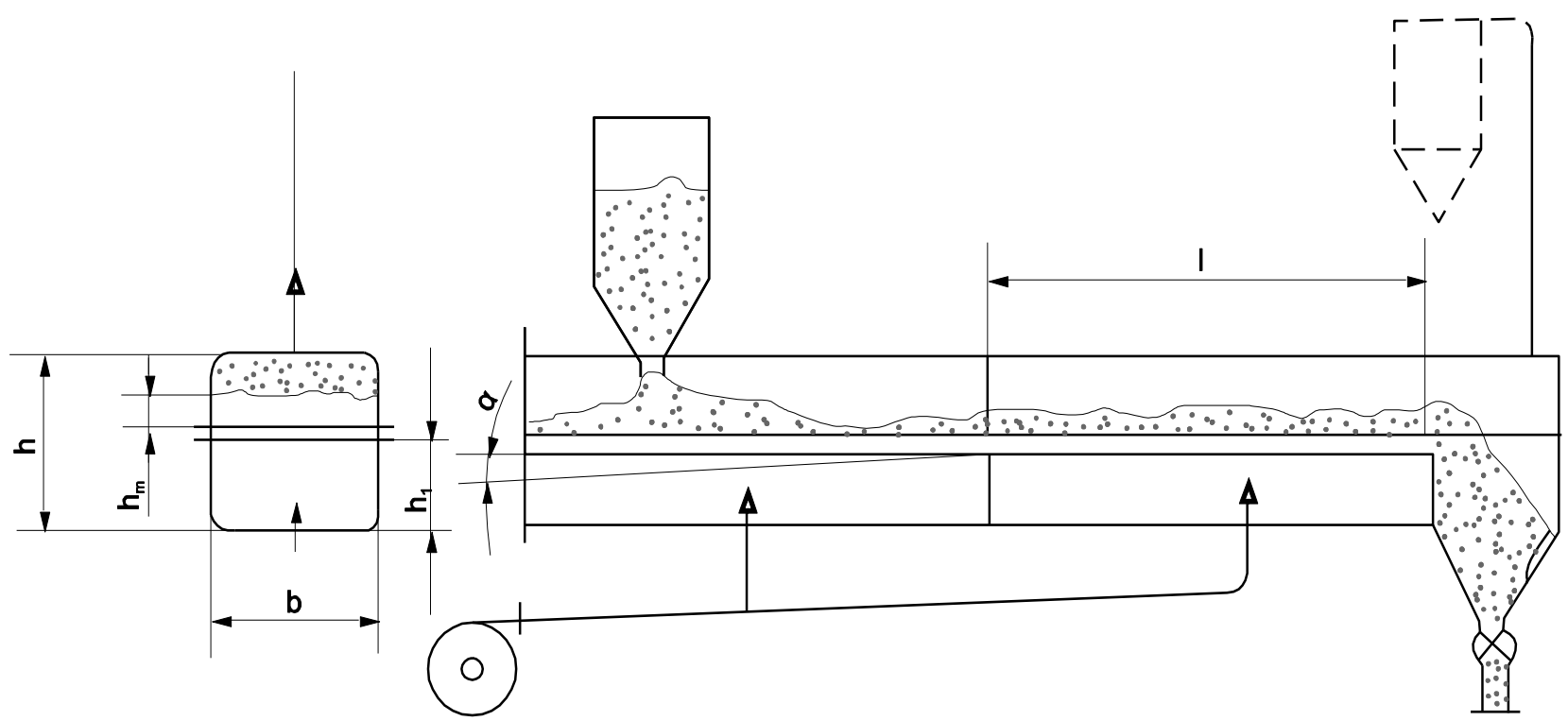

Fig. 3. Air- slide conveyor [4] 
Different types of pneumatic conveying can be split into two groups: transporting the particles by means of air- slide conveyor and transporting the floating particles by means of a pipeline. Air- slide conveyor is a device used for the transport of powdered substances in a closed channel under the influence of gravitational force. The conveyor consists essentially of a channel, divided longitudinally by means of a suitable porous membrane on which the material is conveyed. A sketch of such a system is given in Fig. 3. If a small quantity of low pressure air is fed through the membrane, the inter-particle and particle/wall contact forces will be reduced and the material will behave like a liquid. If a slight slope is imparted to the conveyor, the material will flow. These conveyors are often referred to as 'air -slides'. Air gravity conveyors, ranging in width from 100 to $600 \mathrm{~mm}$, can convey materials over distances of up to $100 \mathrm{~m}$, and are suitable for material flow rates of up to about 3000 tonne/h. In general, most materials in the mean particle size and density ranges from 40 to $500 \mu \mathrm{m}$ and 1400 to $5000 \mathrm{~kg} / \mathrm{m} 3$, respectively, are the easiest to convey and will flow very well down shallow slopes $[2,5]$.

\section{Calculation of air -slide conveyor}

For the known input data, the calculation of the air -slide conveyor was made. The input data for the calculation of the air -slide conveyor are: $d_{c 50}=40 \mu \mathrm{m}$ is middle particle diameter, $\rho_{m}=2100 \mathrm{~kg} / \mathrm{m}^{3}$ is fly ash density, $\rho_{o k}=1,2 \mathrm{~kg} / \mathrm{m}^{3}$ is adopted air density during normal conditions, $\rho_{\varepsilon n}=800 \mathrm{~kg} / \mathrm{m}^{3}$ is bulk density of material, $\eta=17,3 \cdot 10^{-6}$ Pas is dynamic viscosity of air during normal conditions and $\varepsilon_{f}=0,62$.

Air velocity in phase of material aeration is defined by equation:

$$
\begin{aligned}
& v_{v f}=\frac{d_{\check{c} 50}^{2} \cdot\left(\rho_{m}-\rho_{o k}\right) \cdot g}{178 \cdot \eta} \cdot \frac{\varepsilon_{f}^{3}}{1-\varepsilon_{f}}, \\
& v_{v f}=\frac{\left(40 \cdot 10^{-6}\right)^{2} \cdot(2100-1,2) \cdot 9,81}{178 \cdot 17,3 \cdot 10^{-6}} \cdot \frac{0,62^{3}}{1-0,62}=0,671 \cdot 10^{-2} \mathrm{~m} / \mathrm{s} .
\end{aligned}
$$

\subsection{Ratio of heights of material layer during aeration}

Ratio of heights of material layer during aeration is defined by equation:

$$
\frac{h_{m}-h_{f}}{h_{f}}=\varphi_{A} \cdot \frac{\varepsilon_{f}^{3}}{1-\varepsilon_{f}} \cdot\left[\left(\frac{v}{v_{v f}}\right)^{m}-1\right]
$$

where $h_{m}$ is height of material layer during aeration, $h_{f}$ is height of fluidized bed at the minimum velocity, $\varphi_{A}$ is coefficient depending on the porous membrane, $v=10 \cdot v_{v f}$ is air speed calculation on the total surface of the air-slide conveyor (this ratio of velocity depends on the type of material being transported), $v=10 \cdot 0,671 \cdot 10^{-2}=0,0671 \mathrm{~m} / \mathrm{s}$ is air velocity and $m$ $=0,5$ is coefficient of velocity [4],

$$
\begin{aligned}
& \varepsilon_{f}=1-\frac{\rho_{\varepsilon_{n}}}{\rho_{m}}, \\
& \varepsilon_{f}=1-\frac{800}{1200}=0,62 .
\end{aligned}
$$

For $\varepsilon_{f}=0,62$ it obtains $\varphi_{A}=0,6$.

\begin{tabular}{|c|c|c|c|c|c|c|}
\hline Porous membrane & 0,3 & 0,4 & 0,5 & 0,6 & 0,7 & 0,8 \\
\hline Coefficient $\boldsymbol{\varphi}_{\boldsymbol{A}}$ & 1,8 & 1,4 & 1,0 & 0,6 & 0,4 & 0,2 \\
\hline
\end{tabular}

Table 1. Coefficient $\left(\varphi_{A}\right)$ depending on the porous membrane [4]

Ratio of heights of material layer during aeration is defined by equation (2):

$$
\frac{h_{m}-h_{f}}{h_{f}}=0,6 \cdot \frac{0.62^{3}}{1-0.62} \cdot\left[\left(\frac{0,671 \cdot 10^{-1}}{0,671 \cdot 10^{-2}}\right)^{0,5}-1\right]=0,813
$$




$$
\frac{h_{m}}{h_{f}}-1=0,813 \text { and } \frac{h_{m}}{h_{f}}=1,813 .
$$

Density of aerated layer in the channel be calculated according to the following:

$$
\begin{aligned}
& \rho_{\varepsilon}=\rho_{m} \cdot\left(1-\varepsilon_{f}\right) \cdot \frac{h_{f}}{h_{m}}, \\
& \rho_{\varepsilon}=2100 \cdot(1-0,62) \cdot \frac{1}{1,813}=440,154 \frac{\mathrm{kg}}{\mathrm{m}^{3}} .
\end{aligned}
$$

Dynamic viscosity of aerated layer in the channel should be calculated according to the following:

$$
\eta_{\varepsilon}=\eta+K_{\eta} \cdot \frac{1-\varepsilon_{f}}{\varepsilon_{f}} \cdot \frac{v_{v f}\left(\frac{v}{v_{v f}}\right)^{m}}{d_{c 50}^{2}\left(\frac{h_{m}-h_{f}}{h_{f}}\right)^{s}},
$$

where $K_{\eta}=3,7 \cdot 10^{-9}$ Pas is viscosity coefficient, $\eta=17,3 \cdot 10^{-6}$ Pas is dynamic viscosity of air during normal conditions, $d_{c m}=140 \mu \mathrm{m}$ is arithmetic mean diameter of fly ash particles and dispersion coefficient is defined by equation

$$
s=\left(\frac{d_{i m}}{d_{i 50}}\right)^{0,6}=\left(\frac{140}{40}\right)^{0,6}=2,12 .
$$

Dynamic viscosity of aerated layer in the channel should be calculated according to the following (5):

$$
\eta_{\varepsilon}=17,3 \cdot 10^{-6}+3,7 \cdot 10^{-9} \cdot \frac{1-0,62}{0,62} \cdot \frac{0,671 \cdot 10^{-2}}{\left(40 \cdot 10^{-6}\right)^{2}} \frac{\left(\frac{0,671 \cdot 10^{-1}}{0,671 \cdot 10^{-2}}\right)^{0,5}}{(0,813)^{2,12}}=0,046662 \text { Pas. }
$$

\subsection{Channel width}

Channel width (width of the conveyor) can be determined by:

$$
b^{4}\left(1+\frac{0,06}{b}\right)=\frac{M_{m} \cdot \eta_{\varepsilon} \cdot 64}{g \cdot \rho_{\varepsilon}^{2} \cdot \sin \alpha},
$$

where $b$ is channel width, $M_{m}$ is capacity of the material is depending on the part of air -slide conveyor, $M_{m l}=2 \cdot 10,55=21,1$ $\mathrm{t} / \mathrm{h}$ is capacity of materials for two drains on electrostatic precipitators and $\alpha=2^{\circ}$ is angle of inclination. Inserting of obtained values into the equation for determining of channel width, it obtains:

$$
b^{4}\left(1+\frac{0,06}{b}\right)=\frac{21,1 \cdot \frac{1000}{3600} \cdot 0,046662 \cdot 64}{9,81 \cdot 440,154^{2} \cdot 0,0349}=2,64 \cdot 10^{-4} .
$$

Or in the form of equation:

$$
b^{4}+0,06 b^{3}-2,64 \cdot 10^{-4}=0 .
$$

By approximate solving of this equation it obtains channel width of $b=115 \mathrm{~mm}$ and it adopts $b=150 \mathrm{~mm}$.

\subsection{Necessary air quantity for aeration}

Necessary air quantity for aeration be calculated according to the following: 
$Q_{v k}=A_{u k} \cdot \delta$.

The known value of the specific loading on the porous membrane amounts to $\delta=2 \mathrm{~m}^{3} / \mathrm{m}^{2} \mathrm{~min}$ and the total area of air -slide conveyor $A=24,55 \mathrm{~m}^{2}$, so necessary air quantity for aeration for the transport of materials equal to

$Q_{v k}=24,55 \cdot 2=49,1 \mathrm{~m}^{3} / \mathrm{min}$.

\subsection{Total pressure drop}

Total pressure drop in air-slide conveyor when transporting bulk materials can be determined by:

$$
\Delta p_{u k}=\Delta p_{d c}+\Delta p_{p p}+\Delta p_{m}+\Delta p_{o c},
$$

where $\Delta p_{d c}$ is pressure drop across inlet pipeline, $\Delta p_{p p}$ is pressure drop across the porous membrane, $\Delta p_{m}$ is pressure drop across the fluidized bed and $\Delta p_{o c}$ is pressure drop across the outlet pipeline, counting the end of the pipeline on the interlocker.

From practical experience and based on the recommendation of the manufacturer of air-slide conveyor, the company "Claudius Peters" from Hamburg [7], the sum of the pressure drop in the inlet pipeline and the pressure drop on the outlet pipeline is:

$$
\Delta p_{d c}+\Delta p_{o c}=3500 \mathrm{~Pa},
$$

where $\Delta p_{p p}=1000 \mathrm{~Pa}$ is the value given by the producer of the porous membrane.

Pressure drop across the fluidized bed of material in air-slide conveyor be calculated according to the following:

$$
\Delta p_{m}=h_{m} \cdot\left(1-\varepsilon_{f}\right) \cdot\left(\rho_{m}-\rho_{o k}\right) \cdot g,
$$

where $h_{m}=b_{\max } / 2$ is maximum height of the material layer is determined based on the maximum channel width,

$$
\Delta p_{m}=0,075 \cdot(1-0,62) \cdot(2100-1,2) \cdot 9,81=586,8 \mathrm{~Pa} .
$$

Total pressure drop is given by:

$\Delta p_{u k}=3500+1000+586,8=5086,8 \mathrm{~Pa}$.

\subsection{The power of the ventilator motor}

The power of the ventilator motor is calculated according to equation:

$$
N_{e m}=k \cdot \frac{\Delta p_{u k} \cdot Q_{v k} \cdot \frac{\rho_{r a d}}{\rho_{o k}}}{\eta_{v}},
$$

where $k=1,1$ is safety coefficient, $\rho_{\text {rad }}=1,69 \mathrm{~kg} / \mathrm{m}^{3}$ is operating air density in air -slide conveyor, $\rho_{o k}=1,2 \mathrm{~kg} / \mathrm{m}^{3}$ is adopted air density during normal conditions and $\eta_{v}=0,75$ is coefficient of usefulness of ventilator.

Therefore, the power of the ventilator motor be calculated according to the following (10):

$$
N_{e m}=1,1 \cdot \frac{5086,8 \cdot \frac{49,1}{60} \cdot \frac{1,69}{1,2}}{0,75}=8,59 \mathrm{~kW} .
$$

\subsection{Diameter pipeline}

Diameter pipeline can be determined by: 


$$
D_{o s}=\left(\frac{4 \cdot Q_{v k}}{\pi \cdot v_{c j}}\right)^{\frac{1}{2}}
$$

The value of the air velocity in the pipeline is adopted and is equal $v_{c j}=20 \mathrm{~m} / \mathrm{s}$ [4].

Diameter pipeline is given by:

$$
D_{o s}=\left(\frac{4 \cdot \frac{49,1}{60}}{3,14 \cdot 20}\right)^{\frac{1}{2}}=0,228 \mathrm{~m} .
$$

The internal non-standard diameter of the pipeline $\Phi=250 \mathrm{~mm}$ with a wall thickness $\delta=2,5 \mathrm{~mm}$ is adopted.

\section{Conclusion}

With pneumatic conveying systems it is critical that the conveying line inlet air velocity is correctly specified. Because air is compressible, and very much higher air pressures are used in pneumatic conveying than in air-slide conveying, ensuring that the correct inlet velocity is achieved and maintained in a pneumatic conveying system is not a simple matter. If this inlet air velocity is too high the material flow rate may be reduced, the power requirements will be excessive, and operating problems will be severe. With the installation of air-slide conveyors, it will be provided in terms of low power consumption and operating problems associated with abrasive particles, such as erosive wear of system components are almost nonexistent.

In this paper is presented the design calculation of air-slide conveyor in the thermal power plant and the air-slide conveyor is in the process of being installed in the thermal power plant. Based on the known input data, the air velocity in phase of material aeration of the prepared transport material was calculated first, $v_{v f}=0.671 \cdot 10-2 \mathrm{~m} / \mathrm{s}$. Then, the ratio of the layers of the fluid layer is calculated, which depends on the density of aerated layer in the channel $\rho_{\varepsilon}=440,154$ $\mathrm{kg} / \mathrm{m} 3$ and the dynamic viscosity of aerated layer in the channel $\eta_{\varepsilon}=0,046662$ Pas. To determine the channel width, it is necessary to know the capacity of materials for two drains on electro filters, which is $M_{m l}=21,1 \mathrm{t} / \mathrm{h}$. By solving the equation of the fourth degree, the channel width is $b=115 \mathrm{~mm}$, and it is adopted $b=150 \mathrm{~mm}$. In order to determine the air flow required for the transport of the material, the total area of air -slide conveyor $A=24,55 \mathrm{~m}^{2}$ and the specific loading on the porous membrane $\delta=2 \mathrm{~m}^{3} / \mathrm{m}^{2}$ min must be known. The air flow required for the transport of materials is $Q_{v k}=49,1$ $\mathrm{m}^{3} / \mathrm{min}$. Total pressure drop is equal to $\Delta p_{u k}=5086,8 \mathrm{~Pa}$. The air required for the transport of materials in the air troughs is prepared by means of ventilator, therefore it is necessary to determine , the power of the ventilator motor, which is $N_{e m}$ $=8,59 \mathrm{~kW}$. Diameter pipeline is calculated on the basis of the air flow for the transport of materials and is equal to $D_{o s}=$ $0,228 \mathrm{~m}$. The internal non-standard diameter of the pipeline $\Phi=250 \mathrm{~mm}$ with a wall thickness $\delta=2,5 \mathrm{~mm}$ is adopted.

\section{References}

[1] Bogović, I-N., Barišić, B., Katalinić, B., Kršulja, M., Car, Z.,(2011), Digitizing system ATOS - measuring turbo compressor housing, Annals of DAAAM for 2011 \& PROCEEDINGS of the 22nd International DAAAM Symposium / Katalinić, Branko (ur.). - Vienna: DAAAM International Vienna, 2011. 1367-1368 (ISBN: 978- 3901509- 83-4).

[2] Mills D., (2004), Pneumatic Conveying Design Guide, Second Edition, Butterworth-Heinemann, ISBN 0750654716 , UK.

[3] Hadziahmetovic, H. \& Dzaferovic, E., (2009), Ash pneumatic conveying from existing silos no. 4 to two new silos and ash loading in autocisterns - The 20th INTERNATIONAL DAAAM SYMPOSIUM "Intelligent Manufacturing \& Automation: Theory, Practice \& Education", 25-28th November 2009, Vienna, Austria.

[4] Barbalić N., Džaferović E., (2007), Transport čvrstih čestica fluidom, Faculty of Mechanical Engineering Sarajevo, Bosnia and Herzegovina.

[5] Mills D., Jones M.G., Agarwal V.K., (2004), Handbook of Pneumatic Conveying Engineering, CRC Pres.

[6] Hadžiahmetović, H., (2015), Numeričko modeliranje erozije u koljenu pri pneumatskom transportu, Ph.D. Dissertation, Faculty of Mechanical Engineering Sarajevo, Bosnia and Herzegovina.

[7] http://www.claudiuspeters.com/en-GB/documents/358/claudius-peters-pneumatic-conveying-brochure-en.pdf

[8] http://engineering.co.rs/cevni.htm, Accessed on: 2017-08-13. 